\title{
Is the investment-uncertainty relationship non-linear? An empirical analysis for the Netherlands
}

\author{
Hong Bo and Robert Lensink* \\ Faculty of Economics \\ University of Groningen \\ P.O. BOX 800, 9700 AV Groningen \\ The Netherlands \\ email: B.Hong@eco.rug.nl and B.W.Lensink@eco.rug.nl
}

SOM-theme E Financial markets and institutions

\begin{abstract}
We examine the investment-uncertainty relationship for a panel of Dutch manufacturing firms. The system generalised method of moments (GMM) estimates suggests that the effect of uncertainty on investment is non-linear: for low levels of uncertainty an increase in uncertainty has a positive effect on investment, whereas for high levels of uncertainty an increase in uncertainty lowers investment. This result is in line with a number of theoretical studies, but has never been demonstrated empirically.
\end{abstract}

Key words: Firm investment, Uncertainty, Stock Market volatility

JEL Classification: E22, D21

\footnotetext{
* We would like to thank Niels Hermes, Bert Scholtens, Elmer Sterken and two anonymous referees for helpful comments on an earlier version of the paper. We are grateful to Stephen Bond for providing the package of DPD98 for Gauss. The supply of data by Tutein Nolthenius publishers is greatly acknowledged. All errors and omissions remain the sole responsibility of the authors.
} 


\section{Introduction}

The relationship between investment and uncertainty has been examined quite extensively in the last decade. Whereas the investment-uncertainty relationship is unclear from a theoretical point of view, most empirical studies provide evidence for a negative effect of uncertainty on investment. This result is based on empirical models in which the investment-uncertainty relationship is assumed to be linear. However, as suggested by several theoretical studies, the investment-uncertainty relationship might be non-linear. In particular, recent theoretical analyses show that the investment-uncertainty relationship is not monotonic and can probably be represented by an inverted $U$ curve. To our knowledge, there are no studies available which try to test whether there is empirical evidence for positive (decreasing) marginal returns of uncertainty on investment up to a certain threshold level of uncertainty and negative returns of uncertainty on investment thereafter.

This paper provides new empirical evidence on the impact of uncertainty on firm investment. The proposition to be tested is whether low levels of uncertainty have favourable effects, whereas high levels of uncertainty display negative effects. More specifically, using a firm level panel data set for the Netherlands over the 1984-1996 period, we aim to test whether there is empirical support for an inverted $U$ curve investment-uncertainty relationship.

The paper is organised as follows. Section 2 provides a survey of the relevant literature. Section 3 describes the data. Section 4 explains how we measure uncertainty. Section 5 presents regression results for a standard accelerator-type of investment model augmented by an uncertainty proxy. Section 6 tests some alternative investmentuncertainty models. Section 7 concludes.

\section{Literature survey}

There are extensive surveys available on investment under uncertainty, see e.g. Nickell (1978), Dixit and Pindyck (1994), Carruth et al. (2000) and Lensink, Bo and Sterken (2001). Therefore, we are deliberately brief in this paper and refer the reader willing to have a more complete overview to one of these references.

Economic theories do not succeed in predicting a clear-cut relationship between investment and uncertainty. Several characteristics influence the sign and the magnitude 
of the effect of uncertainty on investment. The following list contains the most important factors:

(1) The risk attitude of the firm. Most studies assume that the managers of the firm are risk-neutral. However, Nickell (1978) considers alternative assumptions regarding risk behaviour of firms. Zeira (1990) and Nakamura (1999) theoretically prove that the degree of relative risk aversion alter the effect of uncertainty on investment. Aizenman and Marion (1999), in an empirical cross-country study, pay attention to risk averse behaviour. By modifying the standard expected utility analysis with the concepts of disappointment aversion (Gul, 1991) and Knightian uncertainty, they show that the effect of uncertainty on investment is negative. In general, one can conclude that the probability of a negative effect of uncertainty on investment increases the more risk-averse the firm is.

(2) The degree of irreversibility and the option value of investment opportunities. Dixit and Pindyck (1994) emphasise the consequences of irreversibility and the possibility to wait for the investment-uncertainty relationship. They introduce uncertainty in the investment decision rule through a threshold value that triggers investment and show that uncertainty increases the investment trigger. In a recent influential paper, Guiso and Parigi (1999) try to proxy the firms' perception of risk by using the results of a survey study in which Italian firms are interviewed about their subjective ideas on the variability of future demand for their products. One of their main results is that the effect of uncertainty strongly differs across groups of firms due to differences in the reversibility of investment decisions. Alternatively, Abel and Eberly (1999) argue that even in the case of irreversible investment, uncertainty may have a positive effect in the long-run due to a so-called "hangover" effect. Bar-Ilan and Strange (1999) also point out that uncertainty may have a positive effect on irreversible investment. This might be the case when the intensity of investment is taken into account. However, in general the probability of a negative effect of uncertainty on investment increases the higher the degree of irreversibility.

(3) The degree of financial constraints. Ghosal and Loungani (2000) document that the investment-uncertainty relationship probably depends on the degree of capital market imperfections based on the reasoning given by Greenwald and Stiglitz (1990). A well-developed financial system probably manages risks more efficiently. Moreover, 
in countries with well-developed financial markets it is probably much easier to sell used capital goods, and hence the degree of irreversibility will probably be lower. Therefore, a firm facing an increase in uncertainty will more likely cut investment in the case where it suffers from financial constraints.

(4) The competitiveness in product markets in combination with the production technology. Cabellero (1991) shows that the effect of an increase in uncertainty on irreversible investment is always positive if the firm is operating in a perfect competitive product market using a constant returns to scale production technology. The reason for this positive effect is that in this case the marginal product of capital is a convex function of the uncertainty variable, and hence by means of Jensen's inequality an increase in uncertainty will positively affect investment. For similar analyses, see Hartman (1972) and Abel (1983). Guiso and Parigi (1999) provide evidence that the investment-uncertainty relationship is more negative for firms with more market power.

Most of these studies implicitly assume that the investment-uncertainty relationship is linear. Moreover, the effect of uncertainty on investment is assumed to be either positive or negative. However, some recent theoretical studies suggest that the investmentuncertainty relationship follow an inverted $U$ curve: whereas for low levels of uncertainty the investment- uncertainty relationship is positive, the effect of uncertainty becomes negative for high levels of uncertainty.

Kahneman and Tversky (1979) indirectly provide a theoretical explanation for this inverted $\mathrm{U}$ curve relation. They show that there is risk-seeking behaviour over the domain of small losses if the utility of an agent depends on gains or losses but not final income states. The hypothesis that economic agents do not worry about losses that are smaller than a threshold value has received some support in studies of health insurance (e.g. Marquis and Holmer, 1996; Ellis, 1989). In the case where investment behaviour is derived from a non-linear utility function, a firm would prefer to take some risk over the range of small losses, which are e.g. due to an increase in uncertainty. In this situation, the investment-uncertainty relationship would be positive up to a certain threshold, and negative thereafter. Sarkar (2000) provides another reason why the investment-uncertainty relationship probably can be described by an inverted $U$ curve. He points at two effects of uncertainty on investment. On the one hand, in line with the standard real option 
approach, uncertainty increases the investment threshold and therefore depresses investment. On the other hand, uncertainty increases the probability that the investment threshold will be hit. Therefore, the probability that investment will take place within a specified time period increases. This additional positive "hitting" effect is shown to dominate the negative threshold effect for low levels of uncertainty (see also Price, 1996). Abel and Eberly (1999) also show that low levels of uncertainty increase the expected capital stock while high levels of uncertainty depress investment. In their model this is due to a trade-off between a user costs effect and a hangover effect. Finally, French and Sichel (1993) suggest that firms treat negative and positive shocks asymmetrically. Since negative shocks are often associated with high levels of uncertainty, a negative effect of uncertainty dominates if uncertainty is high whereas a positive effect may appear for low levels of uncertainty.

In spite of the fact that theoretical analyses can explain both positive and negative effects of uncertainty on investment, most empirical papers find evidence for a negative effect (see Lensink, Bo and Sterken, 2001). Moreover, whereas some theoretical studies suggest a non-linear investment-uncertainty relationship with positive effects of low levels of uncertainty and negative effects of high levels of uncertainty, almost the entire empirical investment literature uses investment models in which the investmentuncertainty relationship is assumed to be linear. Unlike the existing empirical literature, this paper tests whether there is empirical support for an inverted $U$ curve relationship between investment and uncertainty for a panel of Dutch firms.

\section{The Data}

Our main data source is the Jaarboek van Nederlandse Ondernemingen. By using data published in the Jaarboek we construct the following variables:

- the capital stock ( $K$ ), which is defined as the book value of fixed assets;

- gross investment $(I)$, which is the sum of the changes in the capital stock and depreciation;

- $\quad$ sales $(S)$, which is defined as the product of output price and products sold;

- the average $Q$, which is constructed by the ratio of the market value of equity plus the book value of debt to the replacement cost of the capital stock and 
- profit $(P T)$, which is defined as operating profits after taxes and before interest payments.

The variables extracted from the Jaarboek are reported on a yearly basis.

We derive the uncertainty proxies $\left(U M_{i t}^{a}\right.$ and $U M_{i t}^{b}$, see the next section) from individual firm's stock market returns, which are calculated by using daily stock market prices as published in DATASTREAM.

The data set covers a stratified sample from all listed Dutch manufacturing firms. We construct a panel of 57 listed Dutch manufacturing firms for the 1984-1996 period. The panel of firms contains 5 firms which are in the textiles industry, 4 in chemicals/oil, 3 in electronics, 5 in building/construction, 5 in metals, 4 in transport equipment, 6 in the food processing industry, 9 in machinery, 2 in paper products, and 14 in "others" (Table 2 lists all firms which we use in the estimates). The sample is restricted to 57 firms for which both stock market data and investment data are available over the entire sample period. The data are not adjusted for inflation since inflation in the Dutch economy during the sample period is almost absent. Table 1 gives some descriptive statistics of the variables used in the estimates.

\section{The proxy for uncertainty}

We derive the uncertainty measure for each individual firm from information on the volatility of individual firms' daily stock market returns. Stock market returns reflect any and all aspects of a firm's environment. This enables us to use a general measure of uncertainty so that the problem of pinpointing the exact source of uncertainty is circumvented (Pindyck, 1986, 1991; Leahy and Whited, 1996). A drawback is that the volatility of stock market returns may be caused by speculative bubbles instead of fundamentals (Ferderer, 1993). Some studies find that only fundamentals are important (e.g. Blanchard, Rhee, and Summers, 1993; Mork, Shleifer, and Vishny, 1990). However, Chirinko and Schaller (1999) find that bubbles boost fixed investment by means of lowering the cost of capital. Therefore, testing the effect of uncertainty on firm investment using stock market volatility is a joint test of the effect of fundamental uncertainty on investment and the impact of stock market bubbles. This requires some caution in interpreting the empirical results. 
We use a General AutoRegressive Conditional Heteroskedastic (GARCH) model to construct the uncertainty proxy. A GARCH model assumes that the variance of the error terms is not constant over time, which has often documented to be the case for stock market returns data.

We construct two measures of uncertainty. ${ }^{1}$ The proxy for the volatility of stock market returns in the base regressions is derived from estimating a GARCH $(1,1)$ model, which is specified as follows:

$$
\begin{aligned}
& R_{t}=\tau_{0}+\tau_{1} R_{t-1}+\varepsilon_{t} \\
& \sigma_{t}^{2}=\varphi_{0}+\varphi_{1} \varepsilon_{t-1}^{2}+\varphi_{2} \sigma_{t-1}^{2}
\end{aligned}
$$

where $R_{t}$ denotes the stock market returns at time $t$ and $\sigma_{t}^{2}$ is the conditional variance of the stock market returns at time $t .^{2}$

The conditional variance of the stock market returns is estimated firm by firm over the entire sample period (1984-1996). This gives us daily conditional variance of stock market returns. Since investment data are only available on a yearly basis, we have to construct a yearly uncertainty measure. We use the following approach. First, we calculate the square root of the daily conditional variances to obtain daily conditional standard deviations. Next, we compute the average of the daily conditional standard deviations of the stock marked returns over each year firm by firm. This uncertainty measure is denoted by $U M_{i t}^{a}$. $^{3}$

The GARCH $(1,1)$ model (equations (1) and (2)) is commonly used to estimate stock market returns volatility. However, it may suffer from a number of problems. First, the conditional mean equation may be wrongly specified. For instance, the forecasting equation of stock market returns may be multivariate. In addition, the mean equation may suffer from remaining serial correlation. Second, there might be additional ARCH effects. Therefore, we construct an alternative uncertainty measure in the following way. We start by estimating a GARCH model specified as: 


$$
\begin{aligned}
& R_{t}=\tau_{0}+\tau_{1} R_{t-1}+\tau_{3} A_{t-1}+\tau_{4} T+\varepsilon_{t} \\
& \sigma_{t}^{2}=\varphi_{0}+\varphi_{1} \varepsilon_{t-1}^{2}+\varphi_{2} \sigma_{t-1}^{2}
\end{aligned}
$$

where $A$ is the average daily stock market returns for all firms in the sample and $T$ is a time trend. $A$ is included in the equation to account for correlation between a firms' stock market returns with other firms'stock market returns, $T$ is added to account for possible time effects.

The next step is to drop insignificant terms from the mean equation and to test the mean equation by considering the Ljung-Box Q-statistic up to 10 lags. This statistic tests for remaining serial correlation in the mean equation. If the p-value of one of the lags is below 0.05 , we respecify the mean equation by taking into account higher order autoregressive terms for $R$ or /and more lags for $A$. We also test additional ARCH effects by using the Lagrange Multiplier (LM) test with five lags. If there are additional ARCH effects we respecify the conditional variance equation and so estimate a higher order GARCH model. In this way we try to identify a specification of the mean and the conditional variance equation for which there is no remaining ARCH effect and for which there is no remaining serial correlation. By estimating this alternative GARCH model, we obtain an alternative series of the daily conditional variance of the stock market returns for each firm. By taking the square root and then averaging it over each year we obtain an alternative uncertainty measure denoted as $U M_{i t}^{b}$.

Table 2 shows which of the variables are significant in the "mean" equation and consequently are taken into account in the estimates (columns 1-5). The table also shows how the conditional variance equation is specified (Column 6). ${ }^{4}$ In addition, the table shows probability values (p-values) for remaining $\mathrm{ARCH}$ effects, based on the ARCH LM test (column 7), as well as p-values of the Ljung-Box Q-statistic to test the relevance of the mean equation (column 8). Note that for one firm, UBBINK, we were not able to find a specification for which the $\mathrm{Q}$ statistic rejects serial correlation at the 5\% significance level. The last two columns give the average value and the standard deviation over the entire sample period of the alternative uncertainty measure $U M_{i t}^{b}$. 


\section{Regression results for an accelerator-type of investment model}

We are primarily interested in the investment-uncertainty relationship. Therefore, we do not try to determine the most sophisticated or the "best" investment equation. This section presents estimation results for a standard accelerator investment model augmented by the uncertainty proxy derived from the volatility of stock market returns. We estimate the following investment equations:

$$
\begin{aligned}
& \left(\frac{I}{K}\right)_{i t}=f_{i}+f_{t}+\beta_{1}\left(\frac{D S}{K}\right)_{i t}+\beta_{2} U M_{i, t+1}^{j}+e_{i t} \\
& \left(\frac{I}{K}\right)_{i t}=f_{i}+f_{t}+\beta_{3}\left(\frac{D S}{K}\right)_{i t}+\beta_{4} U M_{i, t+1}^{j}+\beta_{5}\left(U M_{i, t+1}^{j}\right)^{2}+e_{i t}
\end{aligned}
$$

where $j=a, b . f_{i}, f_{t}$ are firm and time effects. $I_{i t}$ and $K_{i t}$ represent gross investment and the capital stock of firm $i$ at time $t . D S_{i t}$ indicates the changes in sales. $U M_{i t+1}^{j}$ is the uncertainty measure for firm $i$ at time $t+1$, and $j=a, b . e_{i t}$ is an error term. Note that in order to have a forward-looking measure of uncertainty, we use the annual average conditional standard deviation of stock market returns for the year $t+1$ to explain investment in period $t .^{5}$

The proxy for uncertainty is likely to be measured with error and it is an endogenous variable. So, an instrumental variable approach should be used (Pagan and Ullah, 1988). We use the generalised method of moments (GMM) estimation procedure since this is likely to be the most efficient estimation technique. The investment model is estimated by using DPD98 for Gauss (Arellano and Bond, 1998). Since first difference GMM estimators may suffer from weak instruments problems, we adopt the system GMM estimation procedure proposed by Blundell and Bond (1998). In the system GMM estimation procedure, moment conditions for equations in first differences are combined with moment conditions for equations in levels to compute the optimal weighting matrix that provides consistent system GMM estimators. The instruments are chosen based on the principle that the information from the right-hand side variables is used as much as possible until the lowest valid value of the Sargan statistic is obtained. In all estimations 
we control for time effects by adding time dummies from 1984-1996. These time dummies are used as additional instruments.

We start by estimating a linear investment-uncertainty model (equation 5). The first two columns of Table 3 present the results. In line with theory, the coefficient for the changes in sales is highly significant with a positive sign. This confirms the accelerator effect. Both uncertainty proxies $\left(U M_{i t}^{a}\right.$ and $\left.U M_{i t}^{b}\right)$ are significant with a negative sign, which is consistent with most of the empirical literature. To obtain some insights into the economic significance of the uncertainty effect, the standardised regression coefficients for the uncertainty proxy are computed. The bold figures in the table are the standardised estimated coefficients for the uncertainty proxy. Based on the values in columns (1) and (2) of Table 3, a one standard deviation increase in the uncertainty proxy $U M_{i t}^{a}\left(U M_{i t}^{b}\right)$ leads to 0.1585 (0.1902) standard deviation decrease in the investment to capital ratio.

The next step is to consider a possible non-linear uncertainty-investment relationship. Adding a quadratic uncertainty term to the investment model (equation 6) does this. By adding a quadratic uncertainty proxy we aim to test whether the investment-uncertainty relationship can be described by an inverted $\mathrm{U}$ curve. This would be the case if the linear term is significantly positive and the quadratic term is significantly negative. The results are presented in columns (3) and (4) of Table 3. It appears that for both uncertainty measures the linear uncertainty effect becomes significantly positive, whereas the quadratic effect is significantly negative. This confirms the inverted $U$ curve relationship between investment and the uncertainty measure. A one standard deviation increase in the linear uncertainty proxy $U M_{i t}^{a}\left(U M_{i t}^{b}\right)$ leads to 0.8814 (0.6764) standard deviation increase in the investment to capital ratio. At the same time, one standard deviation increase in the quadratic uncertainty measure leads to 1.0456 and 0.9199 standard deviation decrease in the investment to capital ratio for $\left(U M_{i t}^{a}\right)^{2}$ and $\left(U M_{i t}^{b}\right)^{2}$, respectively. The result implies that for low levels of uncertainty the investmentuncertainty relationship is positive, whereas it is negative for high levels of uncertainty.

Table 3 shows that the estimates for the non-linear model meet all necessary tests. The test statistic for the absence of first-order serial correlation in the first-differenced residuals $\left(m_{1}\right)$ is highly significant with a negative sign in all cases, indicating that the 
disturbances $e_{i t}$ are not serially correlated. The test of second order serial correlation $\left(m_{2}\right)$ is not significant, confirming no serial correlation in the error term. The Sargan test statistic supports the validity of the instruments used in the estimation.

\section{Alternative specifications}

To test the robustness of the results presented in Table 3 we estimate some alternative specifications of the investment model. We start by estimating a dynamic investment model by including lagged investment to capital ratio and the lagged value of the changes in sales in equations (5) and (6), respectively. So, we estimate the following models:

$$
\begin{aligned}
& \left(\frac{I}{K}\right)_{i t}=f_{i}+f_{t}+\beta_{6}\left(\frac{D S}{K}\right)_{i t}+\beta_{7} U M_{i, t+1}^{j}+\beta_{8}\left(\frac{I}{K}\right)_{i, t-1}+\beta_{9}\left(\frac{D S}{K}\right)_{i, t-1}+e_{i t} \\
& \left(\frac{I}{K}\right)_{i t}=f_{i}+f_{t}+\beta_{10}\left(\frac{D S}{K}\right)_{i t}+\beta_{11} U M_{i, t+1}^{j}+\beta_{12}\left(U M_{i, t+1}^{j}\right)^{2}+\beta_{13}\left(\frac{I}{K}\right)_{i, t-1}+\beta_{14}\left(\frac{D S}{K}\right)_{i, t-1}+e_{i t}
\end{aligned}
$$

where $j=a, b$. Investment persistence is often considered to be important in an accelerator-type of investment model. Table 4 reports the system GMM estimation results. The table shows that the lagged investment to capital ratio is not significant, whereas the accelerator effect remains. The lagged value of the changes in sales is highly significant in all estimated equations. Again it appears that both uncertainty proxies are significantly negative at the $10 \%$ level when the quadratic term is ignored, whereas the linear uncertainty proxies become significantly positive for the models including the quadratic term. The quadratic term is significantly negative for both uncertainty measures.

There is a recent literature showing that liquidity variables perform well in investment equations. This literature tries to test for financial constraints by considering the investment-cash flow (or profit) sensitivity (Fazarri, et al., 1988). In this paper we do not aim to test for financial constraints. Nevertheless, we present an investment model including a liquidity variable in order to test for the robustness of the investmentuncertainty relationship. ${ }^{6}$ We estimate the following models: 


$$
\begin{aligned}
& \left(\frac{I}{K}\right)_{i t}=f_{i}+f_{t}+\beta_{15}\left(\frac{D S}{K}\right)_{i t}+\beta_{16}\left(\frac{P T}{K}\right)_{i t}+\beta_{17} U M_{i, t+1}^{j}+\varsigma_{i t} \\
& \left(\frac{I}{K}\right)_{i t}=f_{i}+f_{t}+\beta_{18}\left(\frac{D S}{K}\right)_{i t}+\beta_{19}\left(\frac{P T}{K}\right)_{i t}+\beta_{20} U M_{i, t+1}^{j}+\beta_{21}\left(U M_{i, t+1}^{j}\right)^{2}+\varsigma_{i t}
\end{aligned}
$$

where $j=a, b . P T$ is net profits and $\varsigma$ is an error term. The system GMM estimation results are reported in Table 5. It appears that $P T$ is significant at the $10 \%$ significance level, indicating the relevance of a liquidity variable for explaining investment behaviour. The results with respect to the uncertainty measures are more important in the light of this paper. As shown in Table 5, when the investment model is estimated based on the linear hypothesis both uncertainty proxies $U M_{i t}^{a}$ and $U M_{i t}^{b}$ are highly significant with the negative sign. However, the inverted $U$ curve relation between investment and uncertainty is once again confirmed when the investment model is estimated based on the non-linear hypothesis. Therefore, even after we control for a liquidity variable to explain investment, we obtain results that are consistent with the results in our previous estimations.

Finally, we estimate a standard $Q$-model of investment augmented by the uncertainty measures. The equations are specified as follows:

$$
\begin{aligned}
& \left(\frac{I}{K}\right)_{i t}=f_{i}+f_{t}+\beta_{22} Q_{i t}+\beta_{23} U M_{i, t+1}^{j}+v_{i t} \\
& \left(\frac{I}{K}\right)_{i t}=f_{i}+f_{t}+\beta_{24} Q_{i t}+\beta_{25} U M_{i . t+1}^{j}+\beta_{26}\left(U M_{i, t+1}^{j}\right)^{2}+v_{i t}
\end{aligned}
$$

where $j=a, b$. Table 6 reports the GMM estimation results for the $Q$ model. Columns (1) and (2) of Table 6 show that the linear uncertainty proxy is no longer significant in the $Q$-model of investment. This is in line with Leahy and Whited (1996). It appears that $Q$ performs well in the models without a quadratic uncertainty term: the estimated coefficient of $Q$ is positive and highly significant in both cases. However, including the quadratic uncertainty proxy makes $Q$ less significant or even insignificant. Most 
importantly, the estimates for the $Q$-model confirm that the investment-uncertainty relationship can probably be described by an inverted $\mathrm{U}$ curve.

\section{Conclusions}

This paper examines the investment-uncertainty relationship for a panel of Dutch firms. We estimate different investment models including a proxy for uncertainty of stock market returns. The regression outcomes strongly suggest that for low levels of uncertainty there are positive decreasing marginal returns of uncertainty on investment, whereas for high levels of uncertainty the investment-uncertainty relationship becomes negative. This outcome appears to be robust with respect to different specifications of the investment model.

There are several theoretical explanations for the non-linear investment-uncertainty relationship suggested by our empirical analysis. It may be the case that there is risk seeking behaviour for small values of uncertainty. Alternatively, the outcome may be explained by the fact that, on the one hand, an increase in uncertainty increases the investment threshold, whereas, on the other hand, an increase in uncertainty increases the probability that the investment threshold will be hit. A lack of data makes it impossible to test which explanation holds for our panel of firms. However, an obvious subject for future research is to try to determine the underlying reasons for the main outcome of this paper: the inverted $\mathrm{U}$ curve investment-uncertainty relationship. 


\section{References}

Abel, A. B. (1983). Optimal investment under uncertainty. American Economic Review, $73,228-233$.

Abel, A. B. and Eberly, J. C. (1999). The effects of irreversibility and uncertainty on capital accumulation. Journal of Monetary Economics, 44, 339-377.

Aizenman, J. and Marion, N. P. (1999). Volatility and investment: interpreting evidence from developing countries. Economica, 66, 157-79.

Arellano, M. and Bond, S. (1998). Dynamic panel data estimation using DPD98 for gauss: a guide for users. Oxford University.

Bar-Ilan, A. and Strange, W. C. (1999). The timing and intensity of investment. Journal of Macroeconomics, 21(1), 57-77.

Blanchard, O., Rhee, C. and Summers, L. (1993). The stock market, profit, and investment. Quarterly Journal of Economics, February, 115-136.

Blundell, R. and Bond, S. (1998). Initial conditions and moment restrictions in dynamic panel data models. Journal of Econometrics , 87, 115-143.

Caballero, R. J. (1991). Competition and the nonrobustness of the investment-uncertainty relationship. American Economic Review, 81(1), 279-288.

Carruth, A., Dickerson, A., and Henley, A. (2000). What do we know about investment under uncertainty?. Journal of Economics Surveys, 14, 119-153.

Chirinko, R. S. and Schaller, H. (1999). Business fixed investment and "bubbles": the Japanese case. Working Paper, Department of Economics, Emory University, USA. 
Dixit, A. K. and Pindyck, R. S. (1994). Investment under Uncertainty (Princeton University Press).

Ellis, R. P. (1989). Employee choice of health insurance. Review of Economics and Statistics, 71, 215-223.

Fazzari, S.M., Hubbard, G. and Petersen, B. C. (1988). Financing constraints and corporate investment. Brookings Papers on Economic Activity, (1), 141-206.

Ferderer, J. P. (1993). The impact of uncertainty on aggregate investment spending: an empirical analysis. Journal of Money, Credit, and Banking, 25(1), 30-48.

French, M. W. and Sichel, D. E. (1993). Cyclical patterns in the variance of economic activity. Journal of Business \& Economic Statistics, 11(1), 113-119

Ghosal, V. and Loungani, P. (2000). The differential impact of uncertainty on investment in small and large business. Review of Economics and Statistics, 82, 338-349.

Greenwald, B. and Stiglitz, J. (1990). Macroeconomic models with equity and credit rationing. in: Hubbard, G. ed., Asymmetric Information, Corporate Finance, and Investment ( University of Chicago Press), 15-42.

Guiso, L. and Parigi, G. (1999). Investment and demand uncertainty. Quarterly Journal of Economics, 110, 185-227.

Gul, F. (1991). A theory of disappointment aversion. Econometrica, 59, 667-86.

Hartman, R. (1972). The effects of price and cost uncertainty on investment. Journal of Economic Theory, 5, 258-266.

$\mathrm{Hu}, \mathrm{X}$. and Schiantarelli, F. (1998). Investment and capital market imperfections: a switching regression approach using firm panel data. Review of Economics and Statistics, 
$53,466-479$.

Jaarboek van Nederlandse ondernemingen, (1984-1996), Beursmedia vof/Amsterdam Exchanges, the Netherlands

Kahneman, D. and Tversky, A. (1979). Prospect theory: an analysis of decision under risk. Econometrica, 47, 263-291.

Kaplan, S.N. and Zingales, L. (1997). Do investment-cash flow sensitivities provide useful measures of financing constraints?. Quarterly Journal of Economics, 112, 169215.

Leahy, J. V. and Whited, T. M. (1996). The effect of uncertainty on investment: some stylized facts. Journal of Money, Credit, and Banking, 28(1), 64-83.

Lensink, R., Bo, H. and Sterken, E. (2001). Investment, Capital Market Imperfections and Uncertainty: Theory and Empirical Results. Edward Elgar, Cheltenham, UK, forthcoming.

Marquis, M. S. and Holmer, M. R. (1996). Alternative models of choice under uncertainty and demand for health insurance. Review of Economics and Statistics, Vol. LXXVIII, 421-427.

Mork, R., Shleifer, A. and Vishny, R. (1990). The stock market and investment: is the market a sideshow?. Brookings Papers on Economic Activity, 2, 157-215.

Nakamura, T. (1999). Risk-aversion and the uncertainty-investment relationship: A note. Journal of Economic Behaviour \&Organization ,38, 357-363.

Nickell, S.J. (1978). The Investment Decision of Firms Cambridge University Press. Pagan, A. R. and Ullah, A. (1988). The econometric analysis of models with risk terms. Journal of Applied Econometric, 3, 87-105. 
Pindyck, R. S. (1986). Capital risk and models of investment behaviour. M.I.T. Sloan School of Management Working Paper No.1819.

Pindyck, R. S. (1991). Irreversibility and the explanation of investment behaviour. In Lund, D. and Oksendal, B. (eds.), Stochastic Models and Option Values. Amsterdam: North Holland.

Price, S. (1996) Aggregate uncertainty, investment and asymmetric adjustment in the UK manufacturing sector. Applied Economics , 28, 1369-1379.

Sarkar, S. (2000). On the investment-uncertainty relationship in a real options model. Journal of Economic Dynamics \& Control, 24, 219-225.

Zeira, J. (1990) Cost uncertainty and the rate of investment. Journal of Economic Dynamics and Control 14, 53-63. 
Table 1 Summary Statistics

\begin{tabular}{lcccccc}
\hline & Mean & Median & Std.Dev. & Skewness & Kurtosis & Obs. \\
\hline $\mathrm{l} / \mathrm{K}$ & 0.1989 & 0.1947 & 0.2405 & -4.6682 & 55.3123 & 666 \\
$\mathrm{DS} / \mathrm{K}$ & 0.4297 & 0.1879 & 4.4395 & -6.2278 & 172.0821 & 666 \\
$\mathrm{Q}$ & 1.1471 & 1.0292 & 0.4566 & 2.6366 & 15.4425 & 666 \\
$\mathrm{PT} / \mathrm{K}$ & 0.2178 & 0.1494 & 0.3718 & 2.2748 & 20.8196 & 666 \\
$\mathrm{R}$ & 0.00063 & 0.00061 & 0.0014 & 0.1079 & 3.8304 & 666 \\
$\mathrm{UM}^{\mathrm{a}}$ & 0.0178 & 0.0168 & 0.0051 & 0.9563 & 3.8464 & 666 \\
$\left.(\mathrm{UM})^{\mathrm{a}}\right)^{2}$ & 0.00034 & 0.00028 & 0.00021 & 1.7391 & 6.8243 & 666 \\
$\mathrm{UM}^{\mathrm{b}}$ & 0.0179 & 0.0165 & 0.0059 & 1.1715 & 4.4649 & 666 \\
$\left(\mathrm{UM}^{\mathrm{b}}\right)^{2}$ & 0.00036 & 0.00027 & 0.00026 & 2.1048 & 8.4306 & 666 \\
\hline
\end{tabular}

Notes:

(1) Data source: Jaarboek van Nederlands Ondernemingen

(2) Explanations of variables:

I/K: The ratio of gross investment to the capital stock

$\mathrm{DS} / \mathrm{K}$ : The ratio of the changes in sales to the capita stock

$\mathrm{Q}$ : Average $\mathrm{Q}$, which equals the sum of the market value of the stock and the

book value of debt dividede by the replacement cost of the capita stock

$\mathrm{PT} / \mathrm{K}$ : The ratio of net profit to the capital stock

$\mathrm{R}$ : The average stock market returns

$\mathrm{UM}^{\mathrm{a}}$ : The average value of the uncertainty proxy derived from the conditional standard deviations of

stock market returns estimated from the GARCH $(1,1)$ model

$\mathrm{UM}^{\mathrm{b}}$ : The average value of the alternative uncertainty proxy 
Table 2 The specification of the alternative GARCH model

AALBERS

AHOLD

AHREND

AKZO

ALANHERI

AMSTERDAM RUBBER

BAM GROEP

BEERS

BLYDENSTEIN-WILLINK

BOSKALIS

BURGMAN-HEYBROEK

TEN CATE

CSM

VAN DORP DESPEC

DSM

ECONOSTO

ERIKS HOLDING

GAMMA

GETRONICS

GEVEKE

GROLSCH

GRONTMIJ

GTI HOLDING

HAGEMIJER

HEIJNEKEN

HES BEHEER

HOEK LOOS

HBG

IHC CALAND

INTERNATIO-MULLER

KRASNAPOLSKY

MACINTOSH RETAIL

NAEFF

AGRON

NBM-AMSTELLAND

NEDAP

NEDLOYD

NORIT

OCE

PHILIPS

POLYNORM

PORCELYNE FLES

PORCELY

REESIN

SCHUITEMA

SMIT INTERNATIONALE

SMIT INT

DE TELEGRAAF

TEXTIELGROEP

TULIP COMPUTERS

TWENTSCHE KABEL

UBBINK

UNILEVER

WEGENER ARCADE

WEWELER

$R(-1)=$ autoregressive term of stock market return

$A(-1)=$ lagged value of the average value of stock market returns

$\mathrm{C}=$ constant $; \mathrm{T}=$ time trend

HOT $=$ higher order autoregressive terms for $\mathrm{R}$ or higher order lagged terms for $\mathrm{A}$ Specif $=$ specification of the conditional variance equation

$\mathrm{LM}=$ the $\mathrm{p}$ - value of the ARCH LM test

$L B Q=$ the probability $p$-value of the Ljung-Box $Q$ statistic

$\mathrm{MeanUM}^{\mathrm{b}}=$ the average value of the alternative uncertainty proxy for the firm

$\mathrm{StdUM}^{\mathrm{b}}=$ the standard deviation of the alternative uncertainty proxy for the firm

$n$ denotes not significant and not included in the mean equation

$y$ denotes significant and included in the mean equation
GARCH $(1,1)$

$\operatorname{GARCH}(1,1)$

GARCH $(1,1)$

GARCH $(1,1)$

$\operatorname{GARCH}(1,1)$

$\operatorname{GARCH}(1,1)$

GARCH $(1,1)$

GARCH $(1,1)$

GARCH $(1,1)$

GARCH $(1,1)$

GARCH $(1,1)$

$\operatorname{GARCH}(1,1)$

GARCH $(1,1)$

GARCH $(1,1)$

GARCH $(1,1)$

GARCH $(1,1)$

GARCH $(1,2)$

GARCH $(2,1)$

GARCH $(2,1)$

GARCH $(1,1)$

GARCH $(2,1)$

GARCH $(1,1)$

ARCH $(1,2)$

$\operatorname{GARCH}(1,1)$

GARCH $(1,1)$

GARCH $(1,1)$

GARCH $(1,1)$

GARCH $(1,1)$

GARCH $(1,2)$

GARCH $(1,1)$

GARCH $(1,1)$

GARCH $(1,1)$

$\operatorname{GARCH}(2,2)$

GARCH $(1,1)$

GARCH $(1,1)$
$\operatorname{GARCH}(1,2)$

$\operatorname{GARCH}(1,2)$
$\operatorname{GARCH}(1,2)$

$\operatorname{GARCH}(1,2)$

GARCH $(1,1)$

GARCH $(1,1)$

GARCH $(1,1)$

GARCH $(1,1)$

GARCH $(1,1)$

GARCH(1,2)

GARCH $(1,2)$

GARCH $(1,1)$

GARCH $(2,1)$

$\mathrm{ARCH}(4,1)$

GARCH $(2,2)$

$\operatorname{GARCH}(2,1)$

$\operatorname{GARCH}(3,1)$

GARCH $(1,1)$

GARCH $(3,1)$

GARCH $(1,1)$

GARCH $(1,2)$

GARCH $(1,1)$

GARCH

GARCH $(2,1)$
LM

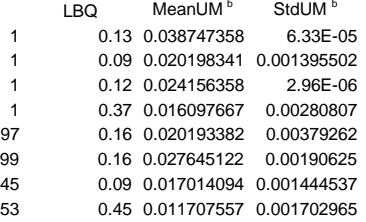
$\begin{array}{llll}0.41 & 0.026227176 & 0.004788766\end{array}$ $\begin{array}{llll}0.2 & 0.0264989 & 0.006670549\end{array}$ $\begin{array}{llll}0.11 & 0.027971215 & 0.001047884\end{array}$ $\begin{array}{llll}0.05 & 0.015700399 & 0.002674126\end{array}$ $\begin{array}{llll}0.08 & 0.012661801 & 0.002631488\end{array}$ $\begin{array}{llll}0.59 & 0.017632473 & 0.002136349\end{array}$ $\begin{array}{rrr}0.32 & 0.01354445 & 0.001271782 \\ 0.13 & 0.014835699 & 0.00113832 \\ 0.18 & 0.013330645 & 0.00187561\end{array}$ $\begin{array}{lll}0.18 & 0.013330645 & 0.00187561\end{array}$ $\begin{array}{lll}0.18 & 0.014665355 & 0.003132355\end{array}$ $\begin{array}{llll}0.18 & 0.014655355 & 0.003132355\end{array}$ $\begin{array}{llll}0.22 & 0.018043886 & 0.002283511 \\ 0.1 & 0.027697373 & 0.001702872\end{array}$ $\begin{array}{lllll}0.1 & 0.027697373 & 0.001702872 \\ 0.11 & 0.014860134 & 0.00126962\end{array}$ $\begin{array}{lllll}0.11 & 0.014860134 & 0.001926962 \\ 0.74 & 0.017278199 & 0.00141315\end{array}$ $\begin{array}{lllll}0.74 & 0.017278199 & 0.001413159\end{array}$ $\begin{array}{lllll}0.73 & 0.011062825 & 0.001835667\end{array}$ $\begin{array}{llll}0.28 & 0.014129682 & 0.002216393\end{array}$ $\begin{array}{llll}0.5 & 0.012534217 & 0.002474855\end{array}$ $\begin{array}{llll}0.39 & 0.030356427 & 0.004889255\end{array}$ $\begin{array}{llll}0.11 & 0.012574724 & 0.00361494\end{array}$ $\begin{array}{llll}0.18 & 0.014364312 & 0.000648201\end{array}$ $\begin{array}{lll}0.22 & 0.018786525 & 0.00446296\end{array}$ $\begin{array}{llll}0.13 & 0.017049217 & 0.002605577\end{array}$ $\begin{array}{lllll}0.06 & 0.019315304 & 0.002093059\end{array}$ $\begin{array}{llll}0.07 & 0.019751633 & 0.001082754\end{array}$ $\begin{array}{lll}0.11 & 0.018238054 & 0.00216304\end{array}$ $\begin{array}{lll}0.71 & 0.012350618 & 0.00033747\end{array}$ $\begin{array}{llll}0.16 & 0.015764906 & 0.004005078\end{array}$ $\begin{array}{llll}0.75 & 0.019215634 & 0.004310661\end{array}$ $\begin{array}{lllll}0.28 & 0.015226481 & 0.002528333\end{array}$ $\begin{array}{llll}0.43 & 0.021533047 & 0.002438248\end{array}$ $\begin{array}{llll}0.46 & 0.018713513 & 0.001210398\end{array}$ $\begin{array}{llll}0.32 & 0.015730762 & 0.002544974\end{array}$ $\begin{array}{lllll}0.45 & 0.018336204 & 0.001946719\end{array}$ $\begin{array}{llll}0.53 & 0.014671316 & 0.001709012\end{array}$ $\begin{array}{llll}0.12 & 0.017123929 & 0.006675567\end{array}$ $\begin{array}{llll}0.12 & 0.017123929 & 0.006675567 \\ 0.13 & 0.012253659 & 0.002560157\end{array}$ $\begin{array}{llll}0.13 & 0.012253659 & 0.002560157\end{array}$ $\begin{array}{llll}0.47 & 0.024343406 & 0.001798266\end{array}$ $\begin{array}{lll}0.29 & 0.0164758790 .000840576\end{array}$ $\begin{array}{llll}0.12 & 0.026408998 & 0.004012563\end{array}$ $\begin{array}{llll}0.23 & 0.017856478 & 0.003327773 \\ 0.45 & 0.012117984 & 0.001721901\end{array}$ $\begin{array}{llll}0.45 & 0.012117984 & 0.001721901 \\ 0.47 & 0.015499012 & 0.003996823\end{array}$ $\begin{array}{llll}0.45 & 0.023807568 & 0.003091593\end{array}$ $\begin{array}{llll}0.64 & 0.014121448 & 0.001345937\end{array}$ $\begin{array}{llll}0.02 & 0.017777931 & 0.002605125\end{array}$ $\begin{array}{llll}0.19 & 0.010876669 & 0.002338691\end{array}$ $\begin{array}{rrr}0.37 & 0.0151298 & 0.002061571 \\ 0.35 & 0.014275185 & 0.00367021\end{array}$ $\begin{array}{llll}0.1 & 0.025028054 & 0.001958428\end{array}$ 
Table 3 Effects of uncertainty on investment: the accelerator model

$$
\begin{array}{ll}
\left(\frac{I}{K}\right)_{i t}=f_{i}+f_{t}+\beta_{1}\left(\frac{D S}{K}\right)_{i t}+\beta_{2} U M_{i t}^{j}+e_{i t} \quad j=a, b \\
\left(\frac{I}{K}\right)_{i t}=f_{i}+f_{t}+\beta_{3}\left(\frac{D S}{K}\right)_{i t}+\beta_{4} U M_{i t}^{j}+\beta_{5}\left(U M_{i t}^{j}\right)^{2}+e_{i t} j=a, b
\end{array}
$$

\begin{tabular}{|c|c|c|c|c|}
\hline & Linear effects & & Nonlinear effects & \\
\hline & 1 & 2 & 3 & 4 \\
\hline \multirow[t]{2}{*}{$\mathrm{DS} / \mathrm{K}$} & 0.0089 & 0.0088 & 0.0094 & 0.0094 \\
\hline & $<9.9978>$ & $<9.0269>$ & $<11.5034>$ & $<11.1823>$ \\
\hline \multirow[t]{3}{*}{$\mathrm{UM}^{\mathrm{a}}$} & -7.4743 & & 41.5663 & \\
\hline & $<-2.1401>$ & & $<2.0551>$ & \\
\hline & -0.1585 & & 0.8814 & \\
\hline \multirow[t]{3}{*}{$\left(U M^{a}\right)^{2}$} & & & -1191.7569 & \\
\hline & & & $<-2.4592>$ & \\
\hline & & & -1.0456 & \\
\hline \multirow[t]{3}{*}{$\mathrm{UM}^{\mathrm{b}}$} & & -7.6002 & & 27.0213 \\
\hline & & $<-1.9598>$ & & $<1.8379>$ \\
\hline & & -0.1902 & & 0.6764 \\
\hline \multirow[t]{3}{*}{$\left(\mathrm{UM}^{\mathrm{b}}\right)^{2}$} & & & & -850.9505 \\
\hline & & & & $<-2.3494>$ \\
\hline & & & & -0.9199 \\
\hline$m_{1}$ & -3.569 & -3.557 & -3.615 & -3.576 \\
\hline $\mathrm{m}_{2}$ & 0.068 & -0.015 & 0.229 & 0.199 \\
\hline Wald test & $\mathrm{H}_{0:} \mathrm{B}_{2}=0$ & $\mathrm{H}_{0}: B_{2}=0$ & $\mathrm{H}_{0:} B_{4}=0$ & $\mathrm{H}_{0:} B_{4}=0$ \\
\hline \multirow[t]{3}{*}{ Chi-square } & 4.5802 & 3.8408 & 4.2233 & 3.378 \\
\hline & & & $\mathrm{H}_{0:} B_{5}=0$ & $\mathrm{H}_{0:} B_{5}=0$ \\
\hline & & & 6.0477 & 5.519 \\
\hline Sargan $(k)$ & $43.846(72)$ & $45.771(72)$ & $40.306(108)$ & $41.661(108)$ \\
\hline \multicolumn{5}{|l|}{ Instruments } \\
\hline & $D S / K_{t-2 \ldots t-4}$ & $\mathrm{DS} / \mathrm{K}_{\mathrm{t}-2 . \ldots \mathrm{t}-4}$ & $D S / K_{t-2 \ldots t-4}$ & $\mathrm{DS} / \mathrm{K}_{\mathrm{t}-2 \ldots \mathrm{t}-4}$ \\
\hline & $\mathrm{UM}_{\mathrm{t}-2 \ldots \mathrm{t}-4}^{\mathrm{a}}$ & $\mathrm{UM}_{\mathrm{t}-2 \ldots \mathrm{t}-4}^{\mathrm{b}}$ & $\begin{array}{l}U^{a}{ }^{a}-2 \ldots t-4 \\
\left(U M^{a}\right)^{2}{ }_{t-2 \ldots t-4}\end{array}$ & $\begin{array}{l}U^{b}{ }^{b} \\
\left.\left(U^{b}\right)^{b}\right)_{t-2 \ldots t-1.4}^{2}\end{array}$ \\
\hline
\end{tabular}

(1) Data source: Jaarboek van Nederlands Ondernemingen

(2) The one-step estimates with robust test statistics are reported

(3) Heterosckedasticity consistent asymptotic t-statistics are in parenthese

(4) $m_{1}$ : test of first-order serial correlation

$\mathrm{m}_{2}$ : test of second-order serial correlation

(5) Sargan(k): Test of the overidentifying restrictions, asymptotically distributed as Chi-square(k) under the null

(6) Time effects are controlled in all estimations by adding time dummies from 1985-1996. These time dummies are also used as additional instruments

(7) Bold figures below t-statistics (given between brackets) are the standardized regression coefficients

(8) Explanations of Variables: see notes for Table 1 
Table 4 Effects of uncertainty on investment: the accelerator model with investment persistence

$$
\begin{array}{ll}
\left(\frac{I}{K}\right)_{i t}=f_{i}+f_{t}+\beta_{6}\left(\frac{D S}{K}\right)_{i t}+\beta_{7} U M_{i t+1}^{j}+\beta_{8}\left(\frac{I}{K}\right)_{i, t-1}+\beta_{9}\left(\frac{D S}{K}\right)_{i, t-1}+e_{i t} & j=a, b \\
\left(\frac{I}{K}\right)_{i t}=f_{i}+f_{t}+\beta_{10}\left(\frac{D S}{K}\right)_{i t}+\beta_{11} U M_{i t+1}^{j}+\beta_{12}\left(U M_{i t+1}^{j}\right)^{2}+\beta_{13}\left(\frac{I}{K}\right)_{i, t-1}+\beta_{14}\left(\frac{D S}{K}\right)_{i, t-1}+e_{i t} & j=a, b
\end{array}
$$

\begin{tabular}{|c|c|c|c|c|}
\hline & Linear effects & & Nonlinear effects & \\
\hline & 1 & 2 & 3 & 4 \\
\hline \multirow[t]{2}{*}{$(\mathrm{l} / \mathrm{K})_{\mathrm{t}-1}$} & -0.0353 & -0.0458 & -0.0581 & -0.0519 \\
\hline & $<-0.9048>$ & $<-1.2945>$ & $<-1.4849>$ & $<-1.4397>$ \\
\hline \multirow[t]{2}{*}{$\mathrm{DS} / \mathrm{K}$} & 0.0103 & 0.0102 & 0.0111 & 0.0109 \\
\hline & $<5.8608>$ & $<5.4379>$ & $<6.1937>$ & $<5.7763>$ \\
\hline \multirow[t]{2}{*}{$(D S / K)_{t-1}$} & 0.0043 & 0.0043 & 0.0049 & 0.0049 \\
\hline & $<2.4135>$ & $<2.3239>$ & $<2.5356>$ & $<2.4785>$ \\
\hline \multirow[t]{3}{*}{$\mathrm{UM}^{\mathrm{a}}$} & -7.0435 & & 38.4589 & \\
\hline & $<-1.7892>$ & & $<1.8126>$ & \\
\hline & -0.1452 & & 0.7928 & \\
\hline \multirow[t]{3}{*}{$\left(U M^{a}\right)^{2}$} & & & -1124.5548 & \\
\hline & & & $<-2.1723>$ & \\
\hline & & & -0.9621 & \\
\hline \multirow[t]{3}{*}{$\mathrm{UM}^{\mathrm{b}}$} & & -7.0403 & & 24.1653 \\
\hline & & $<-1.7467>$ & & $<1.6431>$ \\
\hline & & -0.1712 & & 0.5878 \\
\hline \multirow[t]{3}{*}{$\left(\mathrm{UM}^{\mathrm{b}}\right)^{2}$} & & & & -781.3901 \\
\hline & & & & $<-2.1581>$ \\
\hline & & & & -0.8277 \\
\hline $\mathrm{m}_{1}$ & -4.012 & -4.076 & -3.909 & -3.986 \\
\hline $\mathrm{m}_{2}$ & -0.499 & -0.661 & -0.642 & -0.576 \\
\hline Wald test & $\mathrm{H}_{0:} \mathrm{B}_{7}=0$ & $H_{0:} B_{7}=0$ & $\mathrm{H}_{0:} B_{11}=0$ & $\mathrm{H}_{0:} \mathrm{B}_{11}=0$ \\
\hline \multirow[t]{3}{*}{ Chi-square } & 3.2014 & 3.0508 & 3.2856 & 2.6998 \\
\hline & & & $\mathrm{H}_{0:} B_{12}=0$ & $\mathrm{H}_{0:} B_{12}=0$ \\
\hline & & & 4.7187 & 4.6576 \\
\hline Sargan(k) & $41.947(79)$ & $42.026(79)$ & $41.053(107)$ & $45.308(107)$ \\
\hline \multirow[t]{3}{*}{ Instruments } & $1 / K_{t-3 . \ldots t-4}$ & $\mathrm{l} / \mathrm{K}_{\mathrm{t}-3 . \ldots \mathrm{t}-4}$ & $\mathrm{l} / \mathrm{K}_{\mathrm{t}-3 . \ldots \mathrm{t}-4}$ & $1 / K_{t-3 . . t-4}$ \\
\hline & $D S / K_{t-3 \ldots t-4}$ & $\mathrm{DS} / \mathrm{K}_{\mathrm{t}-3 \ldots \mathrm{t}-4}$ & $\mathrm{DS} / \mathrm{K}_{\mathrm{t}-3 . \ldots t-4}$ & $\mathrm{DS} / \mathrm{K}_{\mathrm{t}-3 \ldots \mathrm{t}-4}$ \\
\hline & $U M^{a}{ }_{t-2 \ldots t-3}$ & $\mathrm{UM}_{\mathrm{t}-2 \ldots \mathrm{t}-3}^{\mathrm{b}}$ & $\begin{array}{l}U M^{a}{ }_{t-2 \ldots t-3}^{2} \\
\left.\left(\mathrm{UM}^{\mathrm{a}}\right)^{2}\right)^{2}-2 \ldots t-3\end{array}$ & $\begin{array}{l}U M^{b}{ }_{t-2 \ldots t-3} \\
\left(U^{b}\right)^{2}{ }^{2}-2 \ldots t-3\end{array}$ \\
\hline
\end{tabular}

Notes:

1) Data source: Jaarboek van Nederlands Ondernemingen

(2) The one-step estimates with robust test statistics are reported

(3) Heterosckedasticity consistent asymptotic t-statistics are in parenthese

(4) $m_{1}$ : test of first-order serial correlation

$\mathrm{m}_{2}$ : test of second-order serial correlation

(5) Sargan(k): Test of the overidentifying restrictions, asymptotically distributed as Chi-square(k)

under the null

(6) Time effects are controlled in all estimations by adding time dummies from 1985-1996. These time

dummies are also used as additional instruments

(7) Bold figures below t-statistics (given between brackets) are the standardized regression coefficients

(8) Bold 
Table 5 Effects of uncertainty on investment: the cash flow model

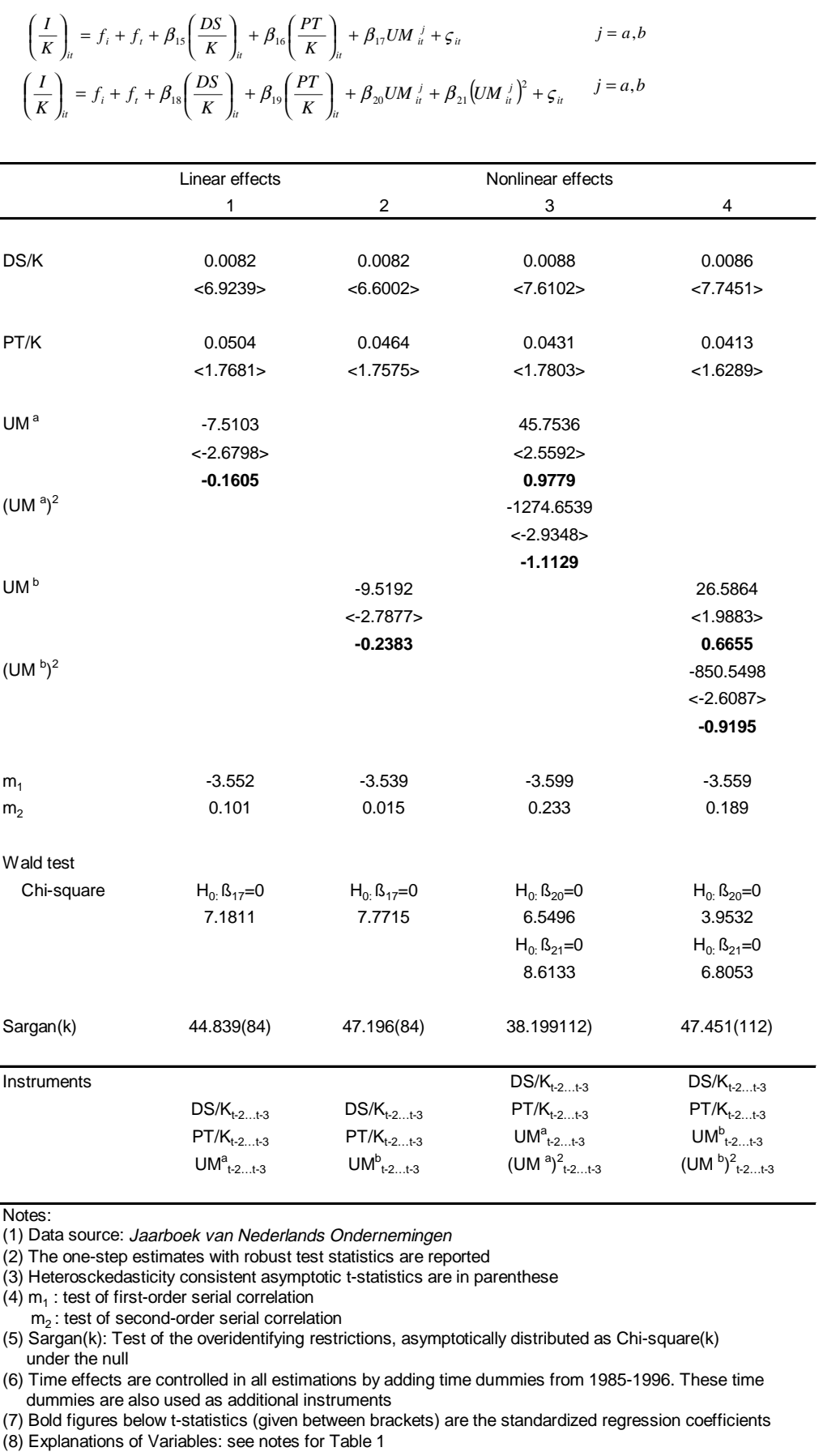


Table 6 Effects of uncertainty on investment: the $Q$ model

$$
\begin{array}{ll}
\left(\frac{I}{K}\right)_{i t}=f_{i}+f_{t}+\beta_{22} Q_{i t}+\beta_{23} U M_{i t}^{j}+v_{i t} & j=a, b \\
\left(\frac{I}{K}\right)_{i t}=f_{i}+f_{t}+\beta_{24} Q_{i t}+\beta_{25} U M_{i t}^{j}+\beta_{26}\left(U M_{i t}^{j}\right)^{2}+v_{i t} & j=a, b
\end{array}
$$

\begin{tabular}{|c|c|c|c|c|}
\hline & Linear effects & & Nonlinear effect & \\
\hline & 1 & 2 & 3 & 4 \\
\hline \multirow[t]{2}{*}{ Q } & 0.1535 & 0.1608 & 0.1269 & 0.1441 \\
\hline & $<2.6395>$ & $<2.8056>$ & $<1.4884>$ & $<1.8082>$ \\
\hline \multirow[t]{3}{*}{$\mathrm{UM}^{\mathrm{a}}$} & -6.6417 & & 52.6721 & \\
\hline & $<-1.6976>$ & & $<2.3592>$ & \\
\hline & -0.1408 & & 1.1169 & \\
\hline \multirow[t]{3}{*}{$\left(U M^{a}\right)^{2}$} & & & -1485.4923 & \\
\hline & & & $<-2.5701>$ & \\
\hline & & & -1.3033 & \\
\hline \multirow[t]{3}{*}{$\mathrm{UM}^{\mathrm{b}}$} & & -7.2092 & & 30.9621 \\
\hline & & $<-1.6662>$ & & $<1.8739>$ \\
\hline & & -0.1805 & & 0.7749 \\
\hline \multirow[t]{3}{*}{$\left(\mathrm{UM}^{\mathrm{b}}\right)^{2}$} & & & & -914.1164 \\
\hline & & & & $<-2.2778>$ \\
\hline & & & & -0.9882 \\
\hline$m_{1}$ & -3.318 & -3.315 & -3.319 & -3.288 \\
\hline $\mathrm{m}_{2}$ & -0.643 & -0.694 & -0.425 & -0.484 \\
\hline Wald test & $\mathrm{H}_{0:} \mathrm{B}_{23}=0$ & $\mathrm{H}_{0:} B_{23}=0$ & $\mathrm{H}_{0}: B_{25}=0$ & $\mathrm{H}_{0:} B_{25}=0$ \\
\hline \multirow[t]{3}{*}{ Chi-square } & 2.8819 & 2.7761 & 5.5658 & 3.5119 \\
\hline & & & $\mathrm{H}_{0}: B_{26}=0$ & $\mathrm{H}_{0:} \mathrm{B}_{26}=0$ \\
\hline & & & 6.6053 & 5.1885 \\
\hline Sargan $(k)$ & $46.599(116)$ & $46.287(116)$ & 47.698(108) & $46.417(108)$ \\
\hline \multicolumn{5}{|l|}{ Instruments } \\
\hline & $Q_{t-2 \ldots t-8}$ & $Q_{t-2 \ldots t-8}$ & $Q_{t-2 \ldots t-4}$ & $Q_{t-2 \ldots t-4}$ \\
\hline & $U M^{a}{ }_{t-2 \ldots t-8}$ & $U M_{t-2 \ldots t-8}^{b}$ & 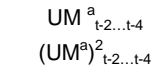 & $\begin{array}{l}U M^{b}{ }_{t-2 \ldots t-4} \\
\left(U M^{b}\right)^{2}{ }_{t-2 \ldots t-4}^{2}\end{array}$ \\
\hline
\end{tabular}

Notes:

(1) Data source: Jaarboek van Nederlands Ondernemingen

(2) The one-step estimates with robust test statistics are reported

(3) Heterosckedasticity consistent asymptotic t-statistics are in parenthese

(4) $m_{1}$ : test of first-order serial correlation

$\mathrm{m}_{2}$ : test of second-order serial correlation

(5) Sargan(k): Test of the overidentifying restrictions, asymptotically distributed as Chi-square(k) under the null

(6) Time effects are controlled in all estimations by adding time dummies from 1985-1996. These time dummies are also used as additional instruments

(7) Bold figures below t-statistics (given between brackets) are the standardized regression coefficients

(8) Explanations of Variables: see notes for Table 1 
Endnotes:

\footnotetext{
${ }^{1}$ In addition to the two measures explained below, a referee suggests to also use the normal standard deviation of stock returns as an alternative uncertainty measure. In some additional estimations of the investment equations we tried to do this (results can be obtained on request). However, the results for this uncertainty measure appear to be insignificant. The insignificant outcome can be explained by the fact that the normal standard deviation does not allow for the time dependence of the second moment and clustering of the data.

${ }^{2}$ We first estimated the mean equation by ordinary least squares (OLS) and tested for possible heteroskedasticiy in the disturbances by using the ARCH LM test. For 54 of the 57 firms this was indeed the case. In order to be consistent, and also since the ARCH terms in the GARCH $(1,1)$ model appear to be significant even for those firms for which an OLS estimate suggests that there are no ARCH effects, we estimate a GARCH model for all firms.

${ }^{3} \mathrm{We}$ also construct an uncertainty measure by using the median of the conditional variances over the sample period (also for the alternative uncertainty measure, see below). Since the results for the estimates based on the median are essentially the same as those based on the mean, we do not present these results.

${ }^{4}$ The regression results can be obtained from the authors on request.

${ }^{5}$ Note that the conditional standard deviations used to construct an uncertainty measure are already one step ahead. However, since the one step ahead (conditional) standard deviations are on a daily basis, and the investment model is estimated on a yearly basis we decided to use the uncertainty measure for $t+1$ in the investment model for period $t$. This makes our proxy for uncertainty forward-looking.

${ }^{6}$ In the "cash-flow" literature it is common to divide firms into subsamples based on criteria which allow the ex ante identification of firms that face the most severe financial constraints. Differences in the investment-cash-flow sensitivities for the subgroups are then used as indicators for differences in financial constraints. However, several authors criticise the a priori classification of firms according to an a priori time invariant measure of financing constraints (see e.g. $\mathrm{Hu}$ and Schiantearelli, 1998). A possibility to avoid this problem would be to interact the liquidity variable with a time-varying variable proxying relevant firm characteristics. However, the use of investment-cash flow (or profit) sensitivities as measures of financial constraint is now severely criticised (see e.g. Kaplan and Zingales, 1997). For these reasons, and since it is not the main aim of this paper to test for financial constraints, we abstract from such an analysis.
} 